\title{
Recommendation of RILEM TC 182 -PEB on bending beam and rheometer measurements of bituminous binders
}

\author{
Prepared by D. Sybilski ${ }^{1}$, A. Vanelstraete ${ }^{2}$ and M. N. Partl ${ }^{3}$ \\ (1) IBDiM, Poland \\ (2) BRRC, Belgium \\ (3) EMPA, Switzerland
}

The text presented hereafter is a draft for general consideration. Comments should be sent to the TC Chairman: Dr. Manfred N. Partl, EMPA, Überlandstrasse 129, CH-8600 Dübendorf, Switzerland; Tel.: +41 182341 13; Fax: +41 1821 62 44; Email: manfred.part1@empa.ch, by 30 April 2005.

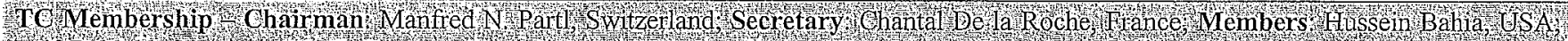

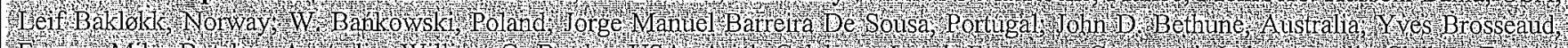

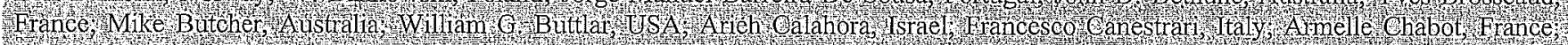

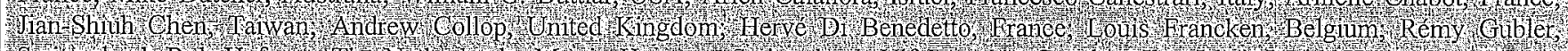

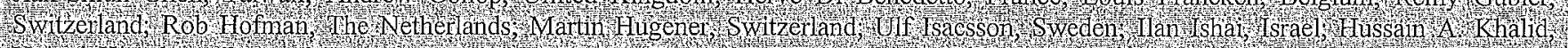

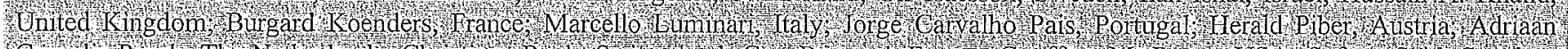

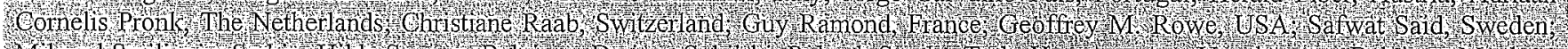

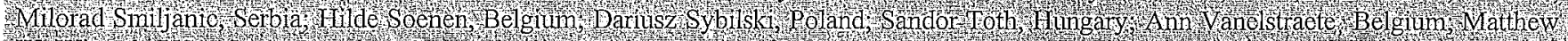

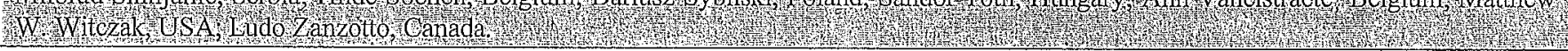

\section{SCOPE}

These recommendations present the results and conclusions of the first and second inter-laboratory tests initiated by two consecutive RILEM Technical Committees TC 152-PBM "Performance of Bituminous Materials" and TC 182-PEB "Performance Testing and Evaluation of Bituminous Materials". The first test was initiated in 1994 [1] and the second one, which was its follow-up, in 1998. Both inter-laboratory tests were led by Task Group TG1 "Bituminous Binders". The aim of the tests was to compare the results of dynamic rheology measurements ${ }^{*}$ of

\footnotetext{
"Even though the term "dynamic" is widely used, it should be underlined that this type of test does not involve any wave propagation inside the sample because the acceleration (or inertia) effects are negligible. Consequently, the test should not be named as "dynamic test". In fact, it is a cyclic test without any significant dynamic effects.
}

bituminous binders. While the first inter-laboratory test was limited to dynamic rheometer (DR) measurements, the second inter-laboratory test also covered rheological testing with bending beam rheometers BBR at low temperatures. Furthermore, the influence of binder ageing, both short and long term, was included in the second inter-laboratory test. Short term ageing was performed according to [2] using rolling thin film oven tests (RTFOT) at $163^{\circ} \mathrm{C}$ and long term ageing according to [3] by applying an additional pressure ageing vessel conditioning (PAV) at $100^{\circ} \mathrm{C}$.

In the DR measurement part of the second interlaboratory test, eighteen laboratories participated in the first phase (tests on original binders) and fourteen laboratories in the second phase (tests after RTFOT and after RTFOT + PAV-ageing). In the BBR part, fourteen laboratories participated in the first phase and ten laboratories in the second phase. 
Four bituminous binders of significantly different chemical composition and rheological properties were submitted to testing:

- No.1 (b1): straight run bitumen used in the LTPP experimental section in Portugal (activities of task group TG4 of RILEM TC PEB [4])

- No.2 (b2): styrene-butadiene-styrene SBS - modified binder (low modification)

- No.3 (b3): SBS - modified binder (high modification)

- No.4 (b4): ethylene vinyl acetate EVA - modified binder. These recommendations focus on the principal achievements. More comprehensive presentations of the results and analysis of both test methods - Dynamic Rheometers and Bending Beam Rheometers - may be found elsewhere [5-7].

\section{BENDING BEAM RHEOMETER MEASUREMENTS}

\subsection{Definition of flexural creep stiffness modulus and $m$-coefficient and critical temperature}

The BBR is used to determine the flexural creep stiffness $S$ and logarithmic creep velocity (m-value) of bituminous binders at low temperatures. A constant load produced by a mass of $100 \mathrm{~g}$ is therefore applied for $240 \mathrm{~s}$ to the midpoint of a simply supported beam of binder, as shown in Fig. 1. The midpoint deflection of the beam versus time is measured.

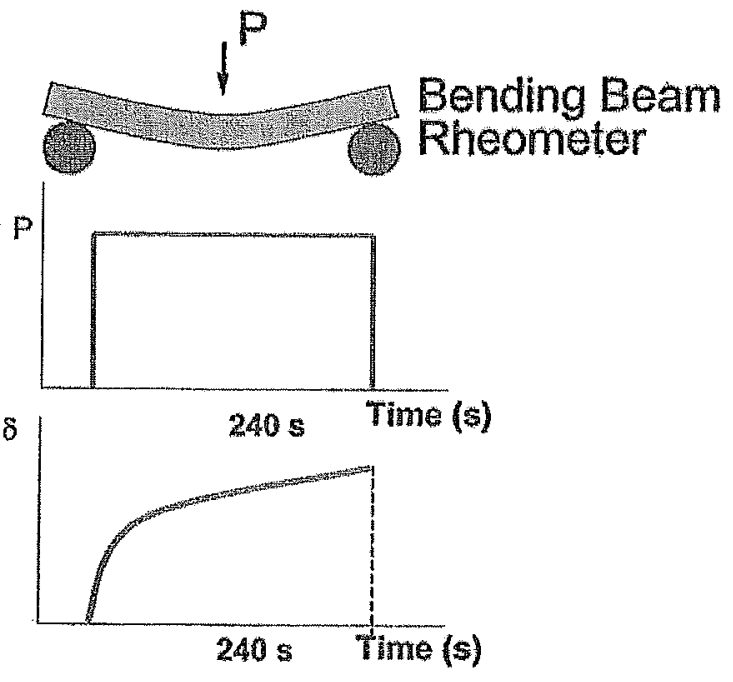

Fig. 1 - Principle of the BBR-test.

The flexural creep stiffness $S(t)$ is the ratio of the maximum bending stress in the beam and the maximum bending strain at a moment of time $t$, and it is calculated from the following equation:

$$
S(t)=\frac{P \cdot l^{3}}{4 \cdot b \cdot h^{3} \cdot \delta(t)}
$$

where:

$S(t) \quad$ creep stiffness at time t, MPa

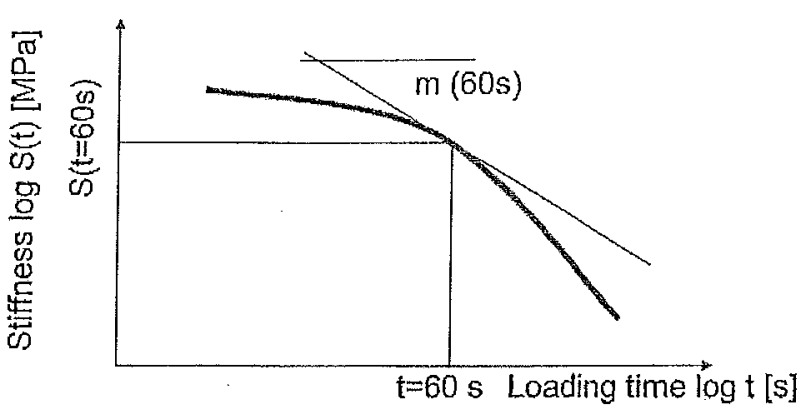

Fig. 2 - Determination of $S(t)$ and $m$ values from BBR test.

$P \quad$ applied constant load $(0.981 \mathrm{~N}), \mathrm{N}$

$l$ distance between beam supports $(102 \mathrm{~mm}), \mathrm{mm}$

$b \quad$ beam width $(12.5 \mathrm{~mm}), \mathrm{mm}$

$h$ beam thickness $(6.25 \mathrm{~mm}), \mathrm{mm}$

$\delta(t) \quad$ deflection at time $t, \mathrm{~mm}$

The value $m(t)$ is defined as the slope of the stiffness vs. time curve in a double logarithmic diagram. In the standard procedure $[5,6]$, both $S$ - and $m$ values are calculated at $60 \mathrm{~s}$ loading time (Fig. 2).

The test method is applicable to binders having flexural stiffness values from $20 \mathrm{MPa}$ to $1 \mathrm{GPa}$. Test results are not valid for beams of asphalt binder that deflect more than $4 \mathrm{~mm}$, or less than $0.08 \mathrm{~mm}$ when tested in accordance with the test method.

For bituminous binders grading purpose (e.g. Superpave Performance Grade) a critical low temperature corresponding to the limiting $\mathrm{S}(\mathrm{t})$ and/or $\mathrm{m}(\mathrm{t})$-value may be defined. This critical temperature is determined by performing the BBR at different testing temperatures.

\subsection{Recommendations for BBR measurements}

\subsubsection{Testing equipment}

It is recommended that the BBR-measurements are performed according to the ASTM-test procedure [8] or the EN test procedure [9].

\subsubsection{Sample preparation}

Thermal history and proper preparation of bituminous binder samples for testing is very important. In some cases this may cause some difficulties, for instance in case of modified binders. Some polymers or other modifiers may produce unstable colloidal systems. Samples must be thoroughly heated and stirred to obtain homogeneous samples and reproducible results.

Heating of bituminous binder should be performed at a proper temperature depending on the binder viscosity and chemical composition. Heating temperature should be high enough to enable sample stirring and homogenisation but on the other hand low enough not to cause excessive binder hardening due to loss of volatile components and oxidation. In the RILEM tests, for instance, reheating temperature of binders was in the range from 135 to $160^{\circ} \mathrm{C}$, depending on the stage and type of binder (higher temperature for aged and polymermodified binders).

Samples prepared for testing should not be stored too long at low temperature to avoid excessive increase in stiffiness due 
to physical hardening [10]. The sample for testing should not be reheated too many times. It is recommended that the sample be reheated at most two times before the test.

\subsubsection{Test conditions}

It is recommended that the mean values of $\mathrm{S}(60 \mathrm{~s})$ and $\mathrm{m}(60 \mathrm{~s})$ from measurements at three temperatures are used to determine the binder critical low temperature corresponding to the $S(60 \mathrm{~s})=300 \mathrm{MPa}$ and $m(60 \mathrm{~s})=0.3 \mathrm{MPa} / \mathrm{s}$. Performance Grade (PG) critical low temperature $T_{P G}$ may be calculated as in Superpave procedure from these results. It is not recommended to determine this Performance Grade temperature from extrapolation of the curves, which may lead to significantly erroneous results (Fig. 3).

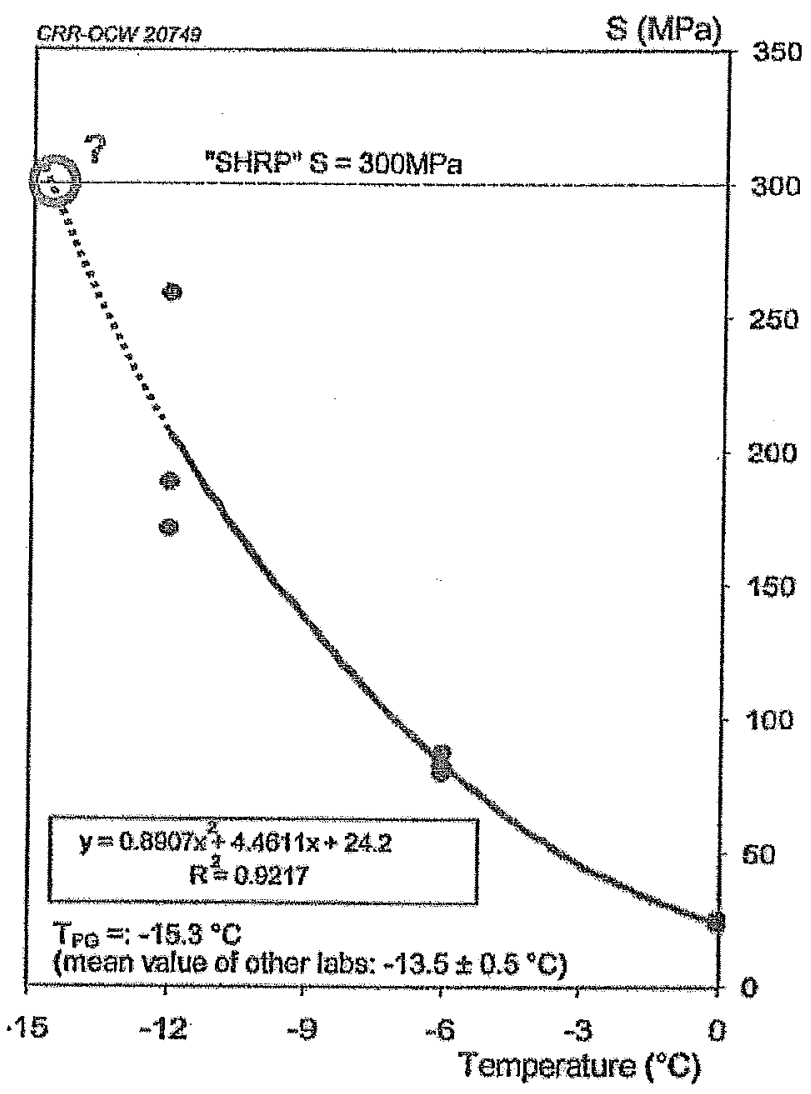

Fig. 3 - Determination of the PG by extrapolation.

Determination of $\mathrm{T}_{\mathrm{PG}} \quad(\mathrm{S}(60 \mathrm{~s})=300 \mathrm{MPa} ; \mathrm{m}(60 \mathrm{~s})=$ $0.3 \mathrm{MPa} / \mathrm{s}$ ) requires three or at least two measurements per temperature.

In case of need to obtain more advanced rheological characterisation of bituminous binder, measurements at more temperatures may be required. For instance, the procedure described in [11] for the development of a master curve combined from low temperature BBR measurements as well as intermediate and high temperature DSR measurements recommends to perform BBR tests at six temperatures.

\subsubsection{Precision of testing: repeatability and reproducibility}

Results of the inter-laboratory test could not directly serve as the basis for the establishment of repeatability and reproducibility as required by ISO 5725-1986 [12]. The set of bending beam rheometers used was too limited for application of this standard procedure. Therefore, statistical analysis of the results was performed by means of classical parameters such as standard deviation, mean value and coefficient of variation.

The following conclusions were drawn from the RILEM inter-laboratory test results as far as the test precision repeatability and reproducibility - is concerned:

- the repeatability coefficient of variation was 2 to $3 \%$ for $\mathrm{S}(60 \mathrm{~s})$ and 1 to $2 \%$ for $\mathrm{m}(60 \mathrm{~s})$ after $60 \mathrm{~s}$ loading, for all samples tested independently from binder ageing stage: original, after RTFOT or after RTFOT + PAV-ageing

- the reproducibility coefficient of variation of stiffness modulus $S$ (mean of 3 repetitions) after $60 \mathrm{~s}$ loading is about $5 \%$, for all samples tested independently from binder ageing stage: original, after RTFO'T or after RTFOT + PAV- ageing

- the reproducibility coefficient of variation of parameter $\mathrm{m}$ (mean of 3 repetitions) after $60 \mathrm{~s}$ loading is 3 to $5 \%$

- precision of critical temperature $\mathrm{T}$ at $\mathrm{S}=300 \mathrm{MPa}$ is about $1^{\circ} \mathrm{C}$ and at $\mathrm{m}=0.3 \mathrm{MPa} / \mathrm{s}$ about $2^{\circ} \mathrm{C}$

- estimation of critical temperature requires at least two repetitions (three repetitions are recommended)

- RTFOT-ageing and PAV-ageing did not influence the reproducibility standard deviation

- repeatability and reproducibility of $S(60 \mathrm{~s})$ and $m(60 \mathrm{~s})$ are of the same level for polymer modified binders than for the plain bitumen.

\subsubsection{Sources of errors}

The following factors were found to have important influence on the result:

- physical hardening of binder may cause its hardening due to micro-molecular changes at low temperature; to avoid this effect, the conditioning time arid temperature must be carefully controlled

- variations of testing temperature due to cooling the moulds in the test bath, containing the specimens tested

- erroneous specimen dimensions - the actual, measured thickness of the moulds should be introduced into the instrument set-up

- improper software - correct BBR software version should be used

- improper position of load - the load should be applied in the centre of the beam

- extrapolation of the stiffness $\mathrm{S}(60 \mathrm{~s})$ versus temperature T curves

- rewriting of data.

\section{DYNAMIC RHEOMETER MEASUREMENTS}

\subsection{Definition of complex modulus and phase angle}

The complex modulus of a viscoelastic material (analogous to elasticity theory either denoted by $\mathrm{E}^{*}, \mathrm{G}^{*}, \mathrm{~K}^{*}$ ) is defined as the ratio between cyclic stress and strain both varying over time or frequency. In asphalt binder technology this complex modulus is also often referred to as "dynamic" modulus, in spite of the fact that testing in most cases is not 
"dynamic" due to negligible inertia effects. Under stress varying with time $\sigma(t)$, due to viscoelastic nature of bituminous materials, strain $\varepsilon(t)$ will reflect dependency on time (frequency) with a time lag called phase angle (with a customary symbol $\delta$ for bituminous binders and $\varphi$ for bituminous mixtures) $[1,13]$ :

$$
\begin{aligned}
& \sigma(t)=\sigma_{0} e^{i \omega t} ; \varepsilon(t)=\varepsilon_{0} e^{i(\omega t-\delta)} \\
& E^{*}(\omega)=\frac{\sigma(t)}{\varepsilon(t)}=\left|E^{*}\right| e^{i \delta}
\end{aligned}
$$

where:

$\left|E^{*}\right|$ norm of the complex modulus (customary called stiffness modulus)

$\sigma_{0} \quad$ stress amplitude

$\varepsilon_{0} \quad$ strain amplitude

$\delta \quad$ phase angle.

$\omega=2 \pi f$ radial frequency, $\mathrm{rad} / \mathrm{s}$, with

f frequency, $\mathrm{Hz}$

i imaginary number.

The complex modulus is a combination of two parts:

$E^{*}=E_{1}+i E_{2}$

DSR

referred to as $E_{1}$ storage modulus and $E_{2}$ loss modulus.

When the load is applied in a sinusoidal function it is appropriate to write the above equations as follows:

$\sigma=\sigma_{0} \sin (\omega t) ; \varepsilon=\varepsilon_{0} \sin (\omega t-\delta)$

$E_{1}=|E *| \cos \delta$

$E_{2}=|E *| \sin \delta$

$\mathrm{E}^{*}$ designates the complex modulus in the axial tension/compression mode of loading. In other modes of loading the complex modulus is designated as $\mathrm{K}^{*}$ in bulk tension/compression or $\mathrm{G}^{*}$ in shear. The latter is mostly applied in bituminous binders testing. Assuming the linear and isotropic behaviour of material the complex moduli are related to each other as follows:

$K^{*}=\frac{E^{*}}{3(1-2 v)}$

$G^{*}=\frac{E^{*}}{2(1+v)}$

with:

$v$ Poisson's ratio, varying from 0.2 to 0.5 (incompressible materials, i.e. $E^{*}=3 G^{*}$ ).

Fig. 4 illustrates shear and strain oscillation and shift (phase angle) between them in DSR measurement ( $\tau$ and $\gamma$ denote shear stress and strain respectively).

\subsection{Recommendations for dynamic rheometer measurements}

\subsubsection{Type of testing equipment and geometry}

Dynamic rheometer is the type of testing equipment applying oscillatory loading on material sample. This type of test allows for material characterisation in a wide range of temperature and frequency. This is particularly important in case of bituminous binders which represent materials having a broad spectrum of relaxation times.

Various types of dynamic rheometers are in use. Configurations applied in the second RILEM interlaboratory test for testing bituminous binders are presented in Fig. 5. However, the dynamic shear rheometer with parallel plates (R-SH-PP) is the most frequently applied (especially after completion of Strategic Highway Research Program SHRP in the USA). In the RILEM inter-laboratory test 16 of all 22 rheometers belonged to this type of equipment.

With regard to test precision, i.e. both in-laboratory repeatability and inter-laboratory reproducibility, it was concluded that for standardisation purposes dynamic shear
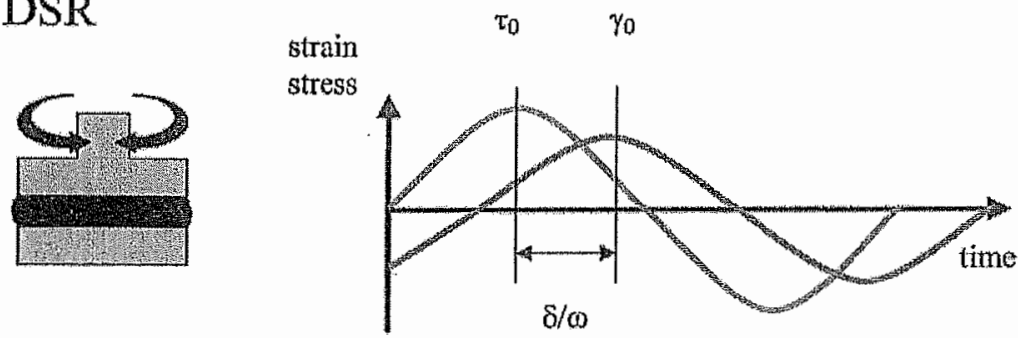

Fig. 4 - Stress and strain oscillation with time in the Dynamic Shear Rheometer measurement.

\begin{tabular}{|c|c|}
\hline Test configuration & Type of loading \\
\hline L-TC-CX & $\begin{array}{c}\text { Linear } \\
\text { Tension - Compression } \\
\text { Cylindrical Sample }\end{array}$ \\
\hline L-SF-AN & $\begin{array}{c}\text { Linear } \\
\text { Annular Shear }\end{array}$ \\
\hline R-SH-PP & $\begin{array}{c}\text { Rotational Sliear } \\
\text { Parallel PIates }\end{array}$ \\
\hline R-SH-CP & Rotational Shear \\
& Cup \& Plate \\
\hline & Torsional Shear \\
\hline
\end{tabular}

Fig. 5 - Test configurations for dynamic rheometer measurements on bituminous binders used in the $2^{\text {nd }}$ RILEM inter-laboratory tests. 
rheometers (rotational parallel shear plates) with sample geometries of to $\phi 25 \mathrm{~mm}$, gap $1 \mathrm{~mm}$ or $\phi 8 \mathrm{~mm}$, gap $2 \mathrm{~mm}$ should only be used for the higher and lower temperature range, respectively.

Other than conventional DSR types of rheometers and geometries may be applied for research purposes, especially for testing at temperatures below $10^{\circ} \mathrm{C}$. Advanced DSR equipment is particularly useful for these purposes.

\subsubsection{Material non-linearity}

For sake of simplicity of material behaviour analysis, it is required that materials are tested in the linear viscoelasticity range. In this range the stress response is directly proportional to the strain tensor and the complex modulus is independent of the strain value. This condition may be fulfilled when dynamic tests are performed at relatively small strains. Deviation from this assumption causes erroneous modulus values. It has been defined that linear region is in the strain range where the complex. modulus differs less than $5 \%$ from its value at zero strain [14]. Airey et cll. [15] recommend 1\% strain for viscoelastic linearity limit for bituminous binders and 100\% strain for polymer network strain limit.

It is of utmost importance to perform the linearity tests prior to testing covering the range of modulus of material tested and sample geometry applied. Fig. 6 presents a simple plot of the relationship of complex modulus $\mathrm{G}^{*}$ from strain value. Procedures for testing linearity of material's behaviour range may be found in AASHTO T 315 (earlier AASHTO TP5-97). More advanced linearity check procedures for rheological tests (DSR, BBR and Direct Tension) may be found in [16].

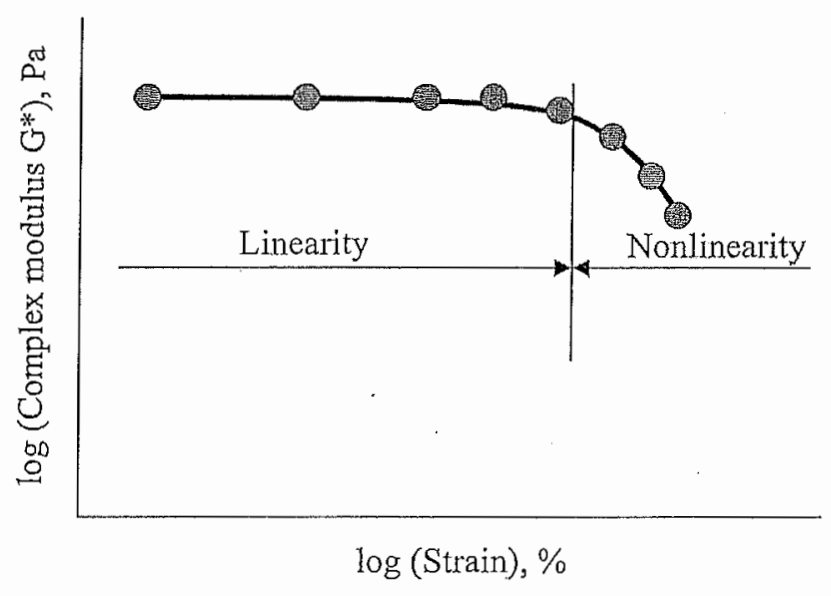

Fig. 6 - Linearity check for DSR.

\subsubsection{Sample preparation}

Similarly to BBR, thermal history and proper preparation of bituminous binder sample for testing is very important. In some cases, however, this may cause some difficulties, for instance in case of modified binders. Some polymers or other modifiers may produce unstable colloidal systems. Samples must be thoroughly heated and stirred to obtain homogeneous samples and reproducible results.

Heating of bituminous binder should be performed at a proper temperature depending on the binder viscosity and chemical composition. Heating temperature should be high enough to enable sample stirring and homogenisation but on the other hand low enough not to cause excessive binder hardening due to loss of volatile components and oxidation. In the RILEM tests, for instance, reheating temperature of binders was in the range from 135 to $160^{\circ} \mathrm{C}$, depending on the stage and type of binder (higher temperature for aged and polymer-modified binders).

Samples prepared for testing should not be stored too long to avoid excesșive increase in stiffiness due to steric hardening, being the process of molecular structuring during storage at room temperature, which may cause significant increase in hardening. The process is reversible after reheating of the binder [10]. The sample for testing should not be reheated too many times. It is recommended that the sample be reheated at most two times before the test.

\subsubsection{Test conditions: temperature and frequency}

Choice of test temperature and frequency for a given geometry is very important. The range of stiffness of sample to be tested depends on the sample geometry itself. For some rheometers, improper combination of temperature - frequency may lead to erroneous results due to insufficient apparatus stiffness. This happens especially at low temperature and high frequency, when the binder stiffness is high. The individual stiffness of an instrument can also interfere with the stiffness measurement of the sample. This effect depends on the specific sample geometry (plate radius and gap). Thus, the test result is erroneous.

There are different methods to verify if measurements are in the stiffness limits:

- compare measurements obtained with various geometries, e.g. plate radii and gap settings; generally:

$\circ$ the larger the plate radius, the lower the maximum reliable sample stiffness

o the thinner the gap, the lower the maximum reliable sample stiffness

o if complex modulus $G^{*}$ value decreases as the gap is decreased, it may be concluded that this is due to the maximum compliance that has been achieved

- check the Black curve (plot of $\mathrm{G}^{*}$ versus phase angle $\delta$, cf. description below); $G^{*}$ value extrapolated to the zero phase angle should be in the range from 2 to $3 \mathrm{GPa}$ corresponding to the stiffness modulus of bituminous binder in the glassy state, otherwise the results at low temperature are not reliable as shown in Fig. 9.

- check the allowable limits for temperature and frequency by plotting stress versus frequency for a given geometry at different temperatures (Fig. 7); the limiting value is found where the stress-frequency curve approaches asymptotically a horizontal maximum line.

Special attention must be paid to test temperature control. It must be kept in mind that bituminous binder is a thermally sensitive viscoelastic material with highly temperature dependent stiffness. Temperature susceptibility of various binders is illustrated in Fig. 8 for unaged binders used in RILEM inter-laboratory test. It depends on binder's composition and temperature range (change in binder stiffness is much more pronounced at lower temperature). Highly polymer-modified binder exhibits significantly different temperature susceptibility than plain bitumen or bitumen with low polymer modification. It could be 


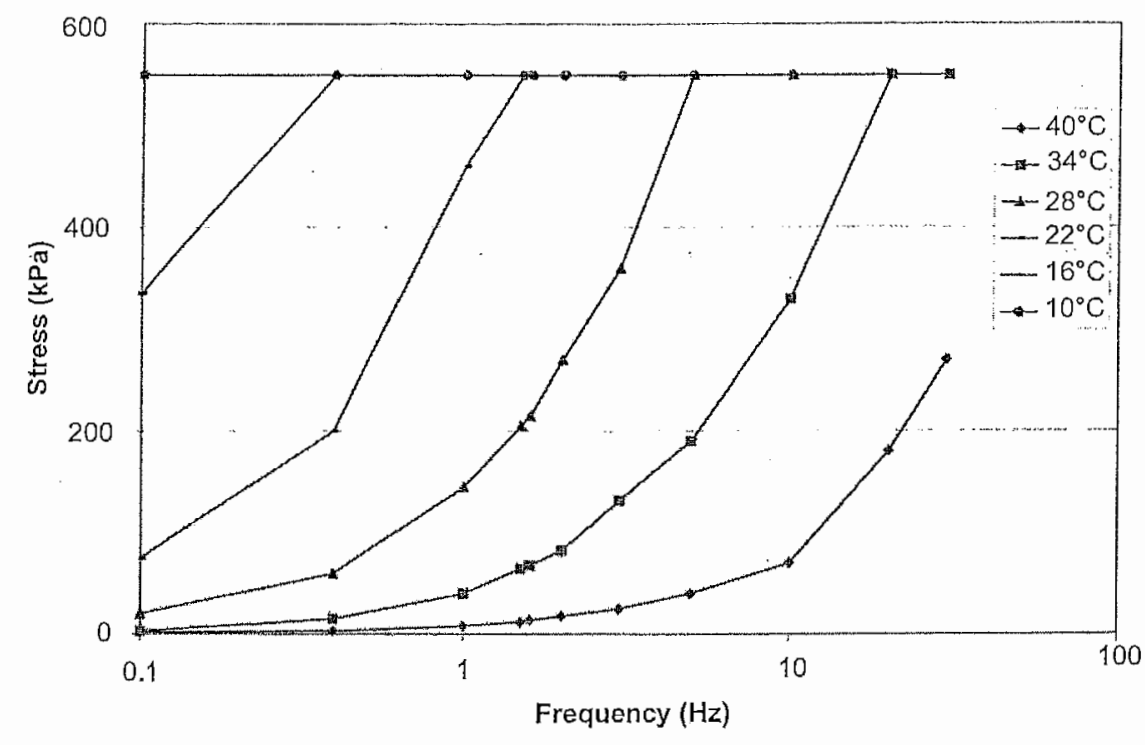

Fig. 7 - Plot of stress versus frequency to check allowable stress limits for temperature and frequency.

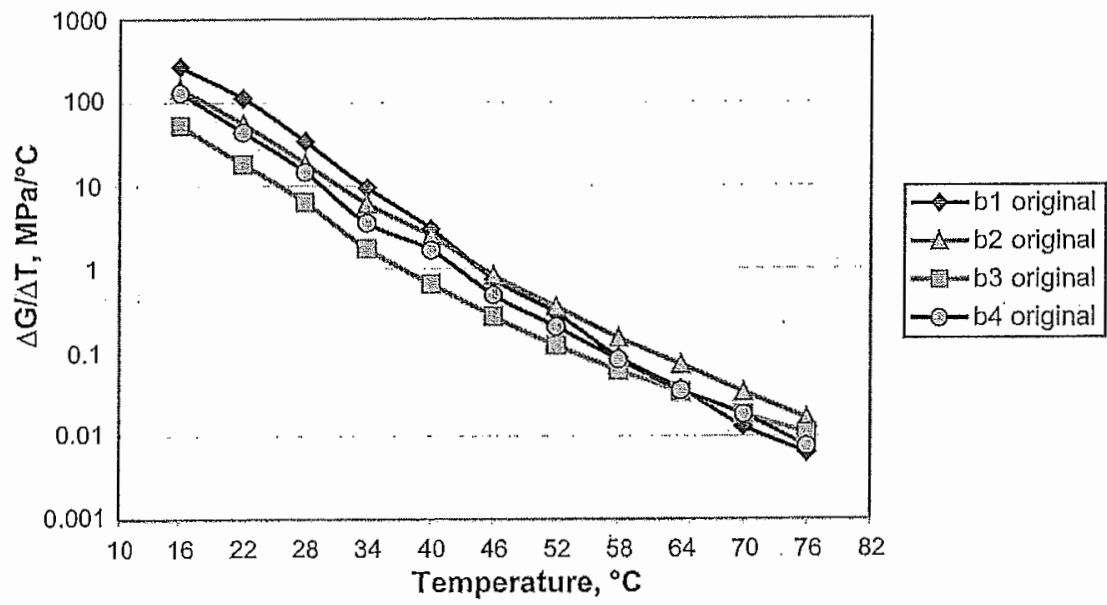

Fig. 8 - Change in complex modulus $\mathrm{G}^{*}$ per $1^{\circ} \mathrm{C}$ for binders tested in RILEM interlaboratory test.

generally noted that temperature change of $1^{\circ} \mathrm{C}$ causes a change in binder's complex modulus from 10 to $40 \%$.

The actual temperature inside the sample should be measured with a calibrated thermocouple. Temperature gradients should also be controlled (cooling and heating of plates, liquid circulating bath, surrounding cooling and heating chamber).

RILEM inter-laboratory tests confirmed that the recommended temperature range for dynamic rheometer measurements should be limited within 10 to $76^{\circ} \mathrm{C}$ due to the low stiffness of a majority of the testing equipment used. Binder stiffness modulus in this temperature range varies from about $10^{2}$ to $10^{9} \mathrm{~Pa}$.

Only in case of advanced and relatively expensive dynamic shear rheometers, it appears possible to expand the testing temperature range to lower temperatures, i.e. down to $-24^{\circ} \mathrm{C}$. Linear rheometers are more suitable for binder testing at low temperature.

To obtain better control of testing temperature and to avoid thermal shocks in the sample, it is recommended to perform tests starting from $25^{\circ} \mathrm{C}$ before proceeding to higher or lower temperatures.

\subsubsection{Precision of testing: repeatability and reproducibility}

Results of the inter-laboratory test could not directly serve as the basis for establishment of repeatability and reproducibility as required by ISO $5725-$ 1986 [12]. The set of rheometers used for complex modulus and phase angle testing was not homogeneous (various apparatuses and geometries). Trial of establishing the values for repeatability and especially reproducibility was not successful because of a relatively small number of participating laboratories using the same equipment and was further reduced by elimination of outliers. Therefore, statistical analysis of the results was performed by means of classical parameters such as standard deviation, mean value and coefficient of variation.

The repeatability and reproducibility for $\mathrm{G}^{*}$ (coefficient of variation) may be practically achieved in the range below $10 \%$, independently from the type of binder, plain or modified, and stage of binder, original as well as RTFOT or PAV-aged.

The repeatability and reproducibility for phase angle may be achieved in the range below $5 \%$ (practically 2 to $3 \%$ ), independently from the type of binder, pure or modified, and stage of binder, original as well as RTFOT or PAV-aged.

\subsubsection{Sources of errors}

Main sources of error for inlaboratory and inter-laboratory precision may be listed as follows:

- non-linearity of material's behaviour (too high strain)

- improper sample geometry: too big plate radius or too thin gap

- too low rheometer stiffness

- deviation of temperature from the target value

- improper sample handling and preparation:

o thermal history

- heterogeneity

- steric hardening (too long storage of the sample)

- deficient or excessive sample volume

- deficient bond between sample and plates

- rewriting of data.

\subsubsection{Black diagram}

Plot of data from dynamic rheometer measurements, complex modulus versus phase angle, called Black diagram, is a simple, yet very practical and powerful tool 

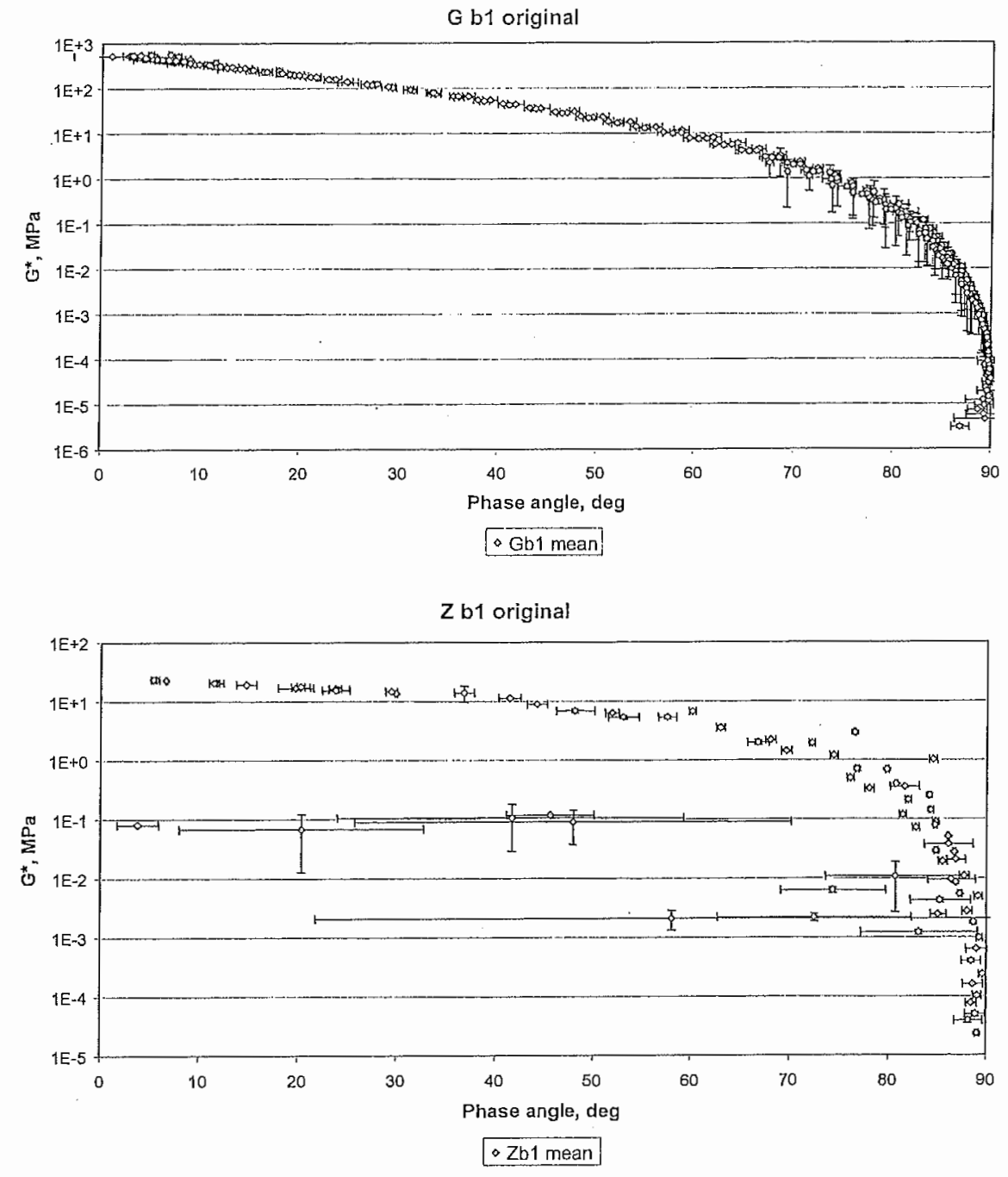

Fig. 9 - Use of Black diagram for detection of outliers (test data are given as mean value and standard deviation, $G$ and $Z$ are the symbols of laboratories and $b 1$ is a symbol of binder tested).

for data analysis. It may be used for verifying the series of data as mentioned earlier, checking the data reliability at low temperatures due to apparatus compliance. It may also be used as a first check for detection of outliers, as shown in Fig. 9, which presents data for the same binder from two laboratories using various theometers and geometries, each performing three repetitions of measurements.

Black curves are often applied for fundamental analysis of the binder rheological behaviour. For instance, it may be analysed for estimation whether a master curve may be produced from data achieved. A range of temperature and frequency as wide as possible is recommended for such an analysis.

\subsubsection{Master curve}

Master curve is a double logarithmic plot of complex modulus or phase angle versus a frequency normalised to a reference or "master" temperature. It is produced by various techniques of shifting of modulus or phase angle values along the horizontal.axis (and/or vertical axis) to obtain one smooth curve of modulus or phase angle. This technique uses temperature-frequency equivalency principle. The advantage of master curve is that the value of complex modulus or phase angle may be estimated for any temperature and frequency covered by the range of master curve.

It should be noted that one must be careful when comparing the master curves - they should be obtained by the same shifting method.

The best known formulas to determine the shift factors are the WLF (Williams-Landel-Ferry) and Arrhenius equations (more detailed information may be found in [1]). A new method was developed lately for combination of high and medium temperature data from DSR and low temperature data from BBR to obtain one over-all master curve [11].

\section{GENERAL CONCLUSIONS}

The $1^{\text {st }}$ and $2^{\text {nd }}$ RUEM interlaboratory tests on binder rheology were very important exercises promoting the discussion between different laboratories, thus contributing to improve quality and competence of the laboratories in performing the fundamental binder tests compared in this study. In addition, well supported data for verification of test precision, both in-laboratory and inter-laboratory, were obtained which can be used on a broader basis by other laboratories worldwide. For example, these results were widely distributed and also delivered as preliminary recommendations to $\mathrm{CEN} \mathrm{TC336} \mathrm{for}$ being taken into consideration in preparation of the new generation of specifications for bituminous binders in Europe.

Both RILEM inter-laboratory tests clearly demonstrated the worldwide need to find a common understanding and assessment of fundamental binder test methods. It may also be a motivation for laboratories to participate in future initiatives which, for instance, could be devoted to an enhanced comparison of different rheometers including newly developed equipment which were not available at that time, e.g. high frequency torsional theometer [17] or the oscillatory squeeze flow rheometer [18]). In this sense, these RILEM interlaboratory tests are an important, but certainly intermediate step.

\section{ACKNOWLEDGEMENTS}

This document was edited by D. Sybilski, A. Vanelstraete and M.N. Partl, who would like' to express their acknowledgements to all participants of the inter-laboratory test for performing the testing and the members of Task Group 1 of TC 182 PEB for their valuable cooperation in elaborating the results, and in preparing these RILEM recommendations. 


\section{REFERENCES}

[1] RILEM Report 17: 'Bituminous Binders and Mixes. State of the Art and Interlaboratory Tests on Mechanical Behaviour and Mix. Design', Edited by L. Francken (E\&FN SPON, 1998).

[2] prEN 12607-1' (1999-version) 'Bitumen and bituminous binders - Determination of the resistance to hardening under the influence of heat and air - Part 1: RTFO'T method'.

[3] AASHTO-PP1-97 'Standard Practice for Accelerated Aging of Asphalt Binder Using a Pressurized Aging Vessel (PAV)'.

[4] Partl, M.N. and Piber, H., 'RILEM - Interlaboratory Tests on Performance Prediction of Pavements', Ninth International Conference on Asphalt Pavements, ISAP, Copenhagen, 17-22 August, 2002.

[5] Vaneistraete, A. and Sybilski, D, 'Results of the RILEM round robin test on bituminous binder rheology', $2^{\text {nd }}$ Eurasphalt \& Eurobitume Congress, Barcelona, Sept. 2000.

[6] Vanelstraete, A. and Sybilski, D., 'Results of the RILEM round robin test on binder rheology', Ninth International Conference on Asphalt Pavements, ISAP, Copenhagen, 17-22 August, 2002.

[7] Sybilski, D. and Vanelstraete, A., 'Precision of bituminous binder rheology tests in the $2^{\text {nd }}$ RIJEM round robin test', PTEBM-conference, Zurich, April 2003.

[8] ASTM D 6648-01, 'Test Method for Determining the Flexural Creep Stiffness of Asphalt Binder using the Bending Beam Rheometer'.

[9] prENxxxx-BBR (Draft 4), 'Bitumen and bituminous binders - Determination of the flexural creep stiffness by the Bending Beam Rheometer (BBR)', 2002-12-19.
[10] Anderson, D.A., Marasteanu, M.O., Mahoney, J.M. and Stephens, J.E., 'Factors affecting the variability in the SHRP binder tests', $79^{\text {th }}$ TRB Annual Meeting, Washington, 2000.

[11] Rowe, G. and Sharrock, M., 'Development of standard techniques for the calculation of master curves for linearviscoelastic materials', Joumal of Applied Asphalt Binder Technology 1(1) (April 2001).

[12] ISO 5725-1986, 'Precision of test methods - Determination of repeatability and reproducibility for a standard test method by inter-laboratory test'.

[13] Di Benedetto, H., Partl, M.N., Francken, L. and De La Roche Saint André, C., 'RILEM TC 182-PEB. Stiffness testing of bituminous mixtures. Recommendations', Mater. Struct., RILEM 34 (236) (2001) 66-70.

[14] Standard Test Method for Determining the Rheological Properties of Asphalt Binder Using a Dynamic Shear Rheometer. AASHTO Designation TP5-97.

[15] Airey, G.D., Rahimzadeh, B. and Collop, A.C., 'Viscoelastic linearity limits for bituminous materials', $6^{\text {th }}$ RILEM Symposium PTEBM'03, Zurich, April 2003.

[16] Marasteamu, M.O. and Anderson, D.A., 'Establishing linear viscoelastic conditions for asphalt binders', $79^{\text {th }}$ TRB Annual Meeting, Washington 2000.

[17] Poulikakos, L., Sayir, M. and Partl, M.N., 'A new highfrequency torsional rheometer for bituminous binders', $6^{\text {th }}$ RILEM Symposium PTEBM'03, Zurich, April 2003.

[18] Bell, D. and Claxton, M.J., 'A novel rheometer for bitumens', $2^{\text {nd }}$ Eurasphalt \& Eurobitume Congress, Barcelona, Sept. 2000. 